\title{
Pengaruh Kondisi Cuaca Terhadap Serangan Hama Penggerek Batang Pada Tanaman Padi Di Desa Ciaruteun Ilir, Kec. Bungbulang, Kab. Bogor
}

\author{
Mochamad Farid Rifai ${ }^{l}$; Yudhi S. Purwanto ${ }^{2}$; Hendra Jatnika ${ }^{3}$; Sely Karmila ${ }^{4}$ \\ 1, 2,3,4Fakultas Telematika Energi, Institut Teknologi PLN \\ ${ }^{1}$ m.farid@itpln.ac.id; \\ 2y.purwanto@itpln.ac.id; \\ 3h.jatnika@itpln.ac.id; \\ 4sely_karmila@itpln.ac.id
}

\begin{abstract}
Erratic climate change is currently affecting various sectors including agriculture, where one of the impacts is the increase in pest populations. Currently the Center for Food and Horticultural Crop Protection (BPTPH) Ciaruteun Ilir Village, Bungbulang Regency, Bogor District in West Java has difficulty in observing and preventing pest attacks, especially stem borer pest. This study discusses the prediction of stem borer attack, especially rice stem. This research focuses on the application of early warning of stem borer pest attacks based on climatological data in the form of temperature, humidity and rainfall data. From this description, the researchers created a web-based stem borer pest attack prediction system using the Naüve Bayes method which was applied based on probability values. Probability values are used to predict future opportunities based on past experiences, so that it will be easier for BPTPH the staff to analyze, identify and monitor the emergence of stem borer pests to be informed to farmers. Based on the 138 data training that has been classified and tested on the pest attack data, the Nä̈ve Bayes method has been successfully predict the present of that attack with 96,76\% accuracy.
\end{abstract}

Keywords: BPTPH, stem borer, Prediction, Nä̈ve Bayes

\begin{abstract}
ABSTRAK
Perubahan iklim yang tidak menentu saat ini berdampak pada berbagai sektor termasuk pertanian, dimana salah satu dampaknya adalah meningkatnya populasi hama. Saat ini Balai Proteksi Tanaman Pangan dan Holtikultura (BPTPH) Desa Ciaruteun Ilir, Kecamatan Bungbulang, Kab. Bogor di Jawa Barat mengalami kesulitan dalam mengamati dan mencegah serangan hama, terutama hama penggerek batang. Penelitian ini membahas mengenai prediksi serangan hama penggerek batang, terutama batang padi. Penelitian ini menitik beratkan pada penerapan peringatan dini serangan hama yang didasarkan pada data klimatologi berupa suhu, kelembaban, dan curah hujan. Dari uraian tersebut, peneliti membuat sistem prediksi serangan hama padi berbasis web menggunakan metode Nä̈ve Bayes yang diterapkan berdasarkan nilai probabilitas. Nilai probabilitas digunakan untuk memprediksi peluang di masa depan berdasarkan pada pengalaman dimasa lalu, sehingga akan memudahkan pegawai BPTPH Desa Ciaruteun Ilir dalam menganalisis, mengidentifikasi dan memantau kemunculan serangan hama penggerek batang untuk diinformasikan kepada pertani. Berdasarkan data training yang berhasil diklasifikasikan 138 data training yang di uji pada data serangan hama metode Naive Bayes berhasil memprediksi adanya serangan hama dengan persentase keakuratan sebesar $96.76 \%$.
\end{abstract}

Kata kunci: BPTPH, hama Penggerek Batang, Prediksi, Nä̈ve Bayes 


\section{PENDAHULUAN}

Perubahan iklim akibat pemanasan global berdampak pada berbagai aspek kehidupan, termasuk sektor pertanian. Perubahan pola curah hujan, meningkatnya frekuensi iklim ekstrim, dan kenaikan suhu udara adalah dampak serius yang dihadapi di Indonesia.

Pertanian merupakan salah satu sektor yang rentan terhadap perubahan iklim. Hal ini berdampak pada produktivitas tanaman, baik tanaman pangan, holtikultura maupun perkebunan. Dampak perubahan iklim terhadap pertanian tidak hanya berupa banjir dan kekeringan, tetapi berdampak juga terhadap populasi hama yang merupakan bagian dari Organisme Pengganggu Tanaman (OPT). Perkembangan hidup hama sangat dipengaruhi oleh suhu, curah hujan, maupun kelembaban udara.

Berdasarkan pelaporan data OPT jenis penggerek batang pada Balai Proteksi Tanaman Pangan dan Holtikultura provinsi Jawa Barat pada tahun 2017 sebanyak 14,517 hektar dan pada tahun 2018 sebanyak 12,713 hektar, faktor penyebabnya adalah iklim sebagai parameter dan variabel penting dalam peramalan serangan hama dan penyakit tanaman khususnya tanaman padi. kondisi iklim saat ini membuat sejumlah lahan pertanian padi di 4 kecamatan di Kabupaten Bogor (Cibungbulang, Ciawi, Ciampea, dan Cibinong) diserang hama ngengat atau penggerek batang padi putih, berbagai upaya yang dilakukan oleh Balai Proteksi Tanaman Pangan \& Holtikultura propinsi Jawa Barat, subwilayah Kab. Bogor dalam mencegah serangan dan penyebaran hama telah dilakukan. Namun sampai saat ini, prediksi hanya dilakukan berdasarkan pengalaman dari tahun ke tahun.

Berdasarkan kondisi tersebut, maka diusulkan suatu sistem yang mampu melakukan prediksi serangan hama tanaman padi menggunakan data klimatologi (berupa suhu, curah hujan, kelembaban udara) agar dapat mengidentifikasi dan memantau kemunculan serangan hama pada tanaman sehingga serangan hama dapat diantisipasi dengan baik. Perhitungan prediksi dilakukan menggunakan metode Naïve Bayes dengan studi kasus yang dilakukan di Desa Ciaruteun Ilir, Kec. Cibungbulang, Kab. Bogor, sedangkan hama tanaman yang akan dianalisis yaitu hama penggerek batang.

Berikut adalah Jurnal penelitian utama yang dijadikan sebagai referensi utama dalam melakukan penelitian, berikut adalah penjelasannya:

Ramazan Bayindir, Mehmet Yesilbudak, Medine Colak, Naci Genc (2018) [1] melakukan penelitian tentang model prediksi energi fotovoltaik yang diusulkan mencapai kinerja yang efektif dan efisien dengan nilai sensitifitas $98,305 \%$ dan nilai akurasi $82,1917 \%$. Selain itu, model yang diusulkan membantu pengguna mengevaluasi dampak dari atribut surya lain pada generasi energi fotovoltaik. Metode yang digunakan Classifier Nä̈ve Bayes dengan data set suhu rata-rata harian, total durasi sinar matahari sehari-hari, jumlah radiasi surya global harian dan parameter pembangkit energi fotovoltaik total harian.

Selanjutnya Luise Suada (2016) [2] melakukan penelitian menegenai tingkat persentase keakuratan dari Sistem Pakar Identifikasi Hama dan Penyakit Tanaman Tebu Menggunakan Metode Nä̈ve Bayes ini setelah dilakukan pengujian mendapat nilai akurasi sebesar 90\%. Metode Nä̈ve Bayes untuk mendiagnosis hama dan penyakit pada tanaman tebu.

Teguh Wahyono, Subanar (2017) [3], [4] melakukan penelitian mengenai penerapan algoritma Naïve Bayes dapat memprediksi ada atau tidaknya kemungkinan serangan hama berdasarkan data historis klimatologi dengan tingkat akurasi yang sangat tinggi, yaitu mencapai 83-100\% dengan ratarata tingkat akurasi mencapai 91,7\%. Sistem peringatan dini ini dikembangkan dengan aplikasi SMS Gateway yang menggunakan aplikasi NowSMS. Dalam penelitian ini, aplikasi tersebut dapat memberikan peringatan dini berbasis SMS baik sebagai notifikasi pada saat registrasi calon member 
baru maupun sebagai warning pada saat permintaan informasi ada atau tidaknya serangan OPT oleh member.

Rifai, Mochamad Farid; Jatnika, Hendra; Valentino, Bowval (2019) [5] [6] Naive Bayes ini mampu memprediksi peluang tingkat kelulusan di masa depan sehingga mempermudah dalam peserta memilih program sertifikasi yang tepat. Sistem ini dapat membantu peserta untuk mendapatkan informasi mengenai tingkat kelulusan peserta berdasarkan kriteria yang dimiliki dan memudahkan peserta untuk menentukan program yang dipilih sehingga efektif dan efisien.

\section{METODOLOGI}

\subsection{Ruang Lingkup}

Adapun ruang lingkup batasan masalah yang dibahas agar lebih terarah dan tidak keluar dari pokok permasalahan yaitu:

a. Penelitian ini dilakukan di Balai Proteksi Tanaman Pangan \& Holtikultura Jawa Barat Sub Wilayah kabupaten Bogor

b. Penelitian dilakukan dengan menggunakan data yang terdapat di Balai Proteksi Tanaman Pangan \& Holtikultura Jawa Barat Sub Wilayah kabupaten Bogor di 4 kecamatan, yaitu: Cibungbulang, Ciawi, Ciampea, dan Cibinong.

c. Penelitian hanya berfokus pada tiga data klimatogi dari Balai Besar Meteorologi Klimatologi Dan Geofisika Jawa Barat berupa suhu, curah hujan, dan kelembaban udara sebagai indikator untuk melakukan prediksi.

d. Penelitian ini menganalisis jenis OPT berupa Penggerek Batang.

e. Sistem informasi yang dibangun adalah berbasis web untuk staf dan admin.

f. Luaran yang dihasilkan berupa informasi mengenai prediksi serangan hama padi berdasarkan data klimatologi kabupaten Bogor.

Metode yang digunakan dalam penelitian ini menggunakan CRISP-DM (Cross-Industry Standart Proccess for Data Mining). Terdapat enam fase dalam CRISP-DM ini yakni dijelaskan pada gambar berikut [7],[8]:

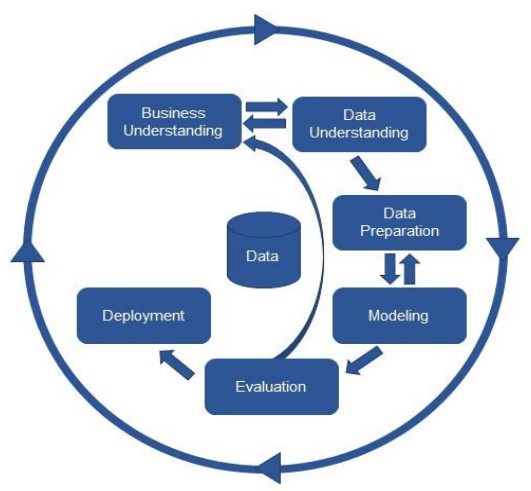

Gambar 1. Metode CRISP-DM

\subsection{Use Case Diagram}

Use case diagram merepersentasikan interaksi antara aktor dan sistem. Dimana pada use case menggambarkan fungsionalitas yang diharapkan pada sistem. Sehingga yang ditekankan pada sistem adalah "apa" yang diperbuat sistem bukan "bagaimana" sistem bekerja [9], [10]. 
PETIR: Jurnal Pengkajian dan Penerapan Teknik Informatika

Vol. 13, No. 2, September 2020, P-ISSN 1978-9262, E-ISSN 2655-5018

DOI: https://doi.org/10.33322/petir.v13i2.1041

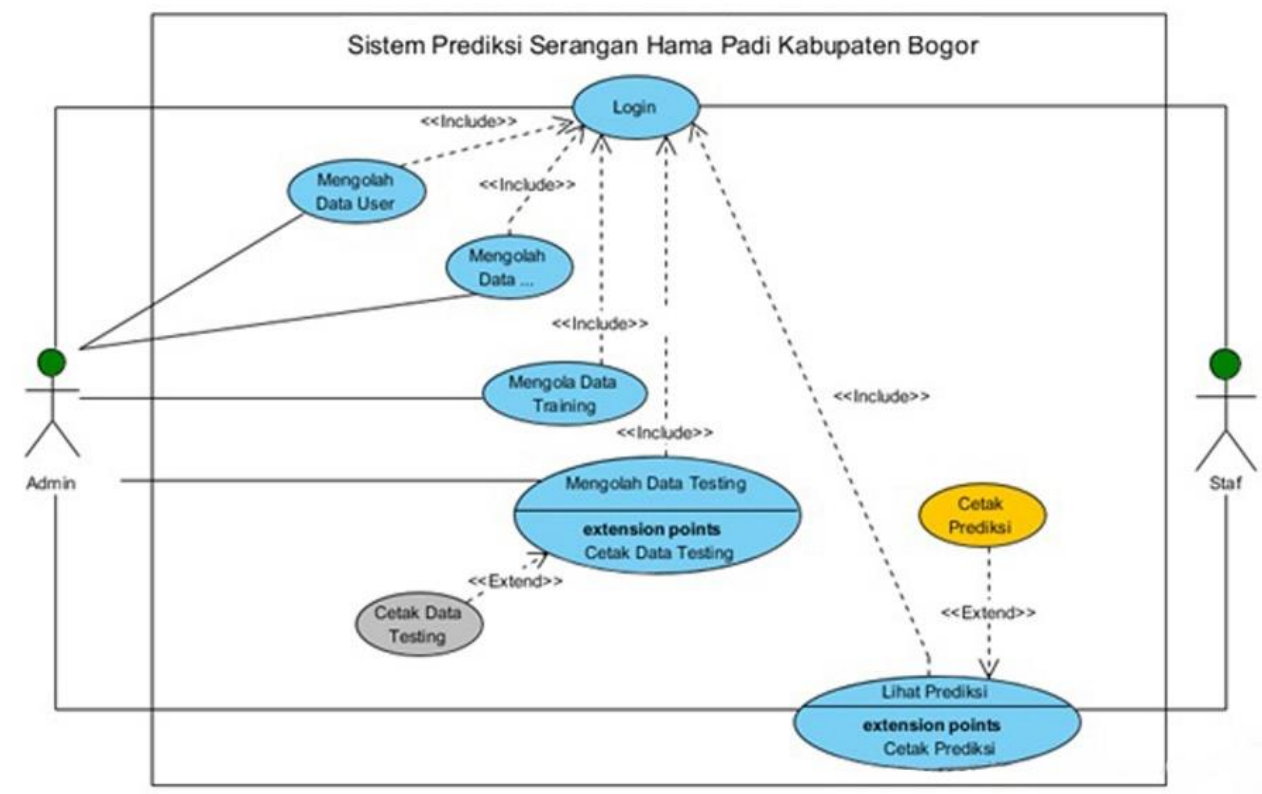

Gambar 2. Use Case Diagram

\section{PENGUJIAN SISTEM}

\subsection{Data Understanding Phase (Fase Pemahaman Data)}

Pada tahap ini akan dilakukan pengumpulan data, jika data berasal lebih dari satu database maka dilakukan proses integrasi data. Pada penelitian ini, data yang digunakan adalah data klimatologi berupa curah hujan, kelembaban, dan suhu udara; dan data serangan hama dari 4 kecamatan di Kabupaten Bogor (Cibungbulang, Ciawi, Ciampea, dan Cibinong) selama kurun waktu 2015-2018. Data yang diperoleh adalah sebagai berikut:

Tabel 1. Data Serangan Hama

\begin{tabular}{|c|c|c|c|c|c|c|}
\hline Kecamatan & No. & Bulan & Suhu(Celcius) & Kelembaban (\%) & CurahHujan(mmibulan) & Serangan Hama \\
\hline \multirow{13}{*}{$\begin{array}{l}\text { Cibung } \\
\text { bulang }\end{array}$} & \multicolumn{6}{|c|}{ Tahun 2016} \\
\hline & & Januari & 28,1 & 88 & 112 & ada \\
\hline & 2 & Februari & 28,1 & 87 & 112 & ada \\
\hline & 3 & Maret & 28,1 & 69 & 65 & tidak ada \\
\hline & 4 & April & 27,1 & 70 & 253 & tidak ada \\
\hline & 5 & Mei & 28,3 & 85 & 221 & add \\
\hline & 8 & Juni & 28,1 & 88 & 161 & ada \\
\hline & 7 & Juli & 28,3 & 90 & 207 & ada \\
\hline & 8 & Agustus & - & - & - & tidak ada \\
\hline & 9 & September & 30,1 & 70 & 62 & tidak ada \\
\hline & 10 & Oktober & 29,3 & 77 & 254 & tidak ada \\
\hline & 11 & November & 28,3 & 70 & 68 & tidak ada \\
\hline & 12 & Desember & - & - & - & tidak ada \\
\hline & & & & & & \\
\hline & & & & & & \\
\hline \multirow{13}{*}{ Ciampea } & \multicolumn{6}{|c|}{ Tahun 2018} \\
\hline & 133 & Januari & 28,1 & 87 & 235 & ada \\
\hline & 134 & Februari & 27,9 & 69 & 32 & tidak ada \\
\hline & 135 & Maret & 28,1 & 87 & 164 & add \\
\hline & 136 & April & 27,7 & 70 & 84 & tidak ada \\
\hline & 137 & Mei & 27,2 & 91 & 393 & tidak ada \\
\hline & 138 & Juni & 26.9 & 91 & 359 & tidak ada \\
\hline & 139 & Juli & 28,1 & 87 & 153 & ada \\
\hline & 140 & Agustus & 27,6 & 79 & 64 & tidak ada \\
\hline & 141 & September & 28,1 & 70 & 27 & tidak ada \\
\hline & 142 & Oktober & 28,5 & 70 & 28 & tidak ada \\
\hline & 143 & November & 27,5 & 85 & 319 & tidak ada \\
\hline & 144 & Desember & 28,1 & 88 & 149 & ada \\
\hline
\end{tabular}




\subsection{Data Preparation Phase (Fase Pengolahan Data)}

Pada tahap ini, dilakukan proses seleksi data dan transformasi data. Data yang sudah digunakan akan diolah di fase pengolahan data.

\subsection{Data Selection (Seleksi Data)}

Proses penyeleksian data dilakukan karena tidak semua data akan digunakan, sehingga seleksi data sangat dibutuhkan. Data yang diambil adalah data yang sesuai dengan analisis yang digunakan. Peneliti hanya menggunakan beberapa data, yaitu sebagai berikut:

Tabel 2. Data Seleksi

\begin{tabular}{|r|r|r|r|l|}
\hline No. & Suhu(Ccelcius) & Kelembaban(\%) & Curah Hujan(mmihari) & Serangan Hama \\
\hline 1 & 28,1 & 88 & 112 & ada \\
\hline 2 & 28,1 & 87 & 112 & ada \\
\hline 3 & 28,1 & 69 & 65 & tidak ada \\
\hline 4 & 27,1 & 70 & 253 & tidak ada \\
\hline 5 & 28,3 & 85 & 221 & ada \\
\hline 6 & 28,1 & 88 & 161 & ada \\
\hline 7 & 28,3 & 90 & 207 & ada \\
\hline 8 & 30,1 & 70 & 62 & tidak ada \\
\hline 9 & 29,3 & 77 & 254 & tidak ada \\
\hline 10 & 28,3 & 70 & 68 & tidak ada \\
\hline
\end{tabular}

\begin{tabular}{|r|r|r|l|}
\hline & & & \\
\hline 133 & 28,1 & 87 & \\
\hline 134 & 27,6 & 79 & 153 \\
\hline 135 & 28,1 & 70 & 64 tidak ada \\
\hline 136 & 28,5 & 70 & 27 tidak ada \\
\hline 137 & 27,5 & 85 & 28 tidak ada \\
\hline 138 & 28,1 & 88 & 319 tidak ada \\
\hline
\end{tabular}

\subsection{Data Transformation (Transformasi Data)}

Data yang telah di seleksi selanjutnya akan diproses lagi pada tahap pengubahan data. Tahap pengubahan data merupakan penggabungan data dengan melakukan pengklasifikasian menjadi beberapa kategori. Berikut tabel pengklasifikasian data:

a. Suhu

Variabel ini berisi range nilai yang telah diklasifikasikan menjadi 3 kategori yaitu Rendah, Sedang, Tinggi. Berikut adalah suhu yang telah diklasifikasikan:

Tabel 3. Klasifikasi Suhu

\begin{tabular}{|c|c|}
\hline Suhu $\left({ }^{\mathbf{}} \mathbf{C}\right)$ & Kategori \\
\hline$<24$ & Rendah \\
\hline $24-32$ & Sedang \\
\hline$>33$ & Tinggi \\
\hline
\end{tabular}

b. Kelembaban Udara

Variabel ini berisi range nilai yang telah diklasifikasikan menjadi 3 kategori yaitu Rendah, Sedang, Tinggi. Berikut adalah kelembaban udara yang telah diklasifikasikan: 
PETIR: Jurnal Pengkajian dan Penerapan Teknik Informatika

Vol. 13, No. 2, September 2020, P-ISSN 1978-9262, E-ISSN 2655-5018

DOI: https://doi.org/10.33322/petir.v13i2.1041

Tabel 3. Klasifikasi Kelembaban Udara

\begin{tabular}{|c|c|}
\hline Kelembaban Udara (\%) & Kategori \\
\hline$<70$ & Rendah \\
\hline $71-90$ & Sedang \\
\hline$>91$ & Tinggi \\
\hline
\end{tabular}

c. Curah Hujan

Variabel ini berisi range nilai yang telah diklasifikasikan menjadi 4 kategori yaitu Rendah, Menengah, Tinggi, dan Sangat Tinggi. Berikut adalah curah hujan yang telah diklasifikasikan:

Tabel 4. Klasifikasi Curah Hujan

\begin{tabular}{|c|c|}
\hline Kelembaban Udara (mm) & Kategori \\
\hline $0-100$ & Rendah \\
\hline $100-300$ & Sedang \\
\hline $300-400$ & Tinggi \\
\hline$>400$ & Sangat Tinggi \\
\hline
\end{tabular}

d. Prediksi Serangan

Variabel prediksi serangan merupakan class atau data yang berfungsi untuk menentukan hasil dari adanya serangan hama. Dalam pengelompokan data sudah ditentukan secara tetap agar tidak terjadi kesalahan dalam proses perhitungan program. Data keputusan prediksi serangan memiliki dua nilai yaitu "ADA" dan "TIDAK ADA" Data kategori di atas kemudian diklasifikasikan. Di bawah ini merupakan data yang telah diklasifikasikan tersebut.

Tabel 5. Data Transformasi

\begin{tabular}{|c|c|c|c|c|}
\hline No. & Suhu(Celcius) & Kelembaban[\%] & Curah Hujan(mmihari) & Serangan Hama \\
\hline 1 & sedang & sedang & menengah & ada \\
\hline 2 & sedang & sedang & menengah & ada \\
\hline 3 & sedang & rendah & rendah & tidak ada \\
\hline 4 & sedang & rendah & menengah & tidak ada \\
\hline 5 & sedang & sedang & menengah & ada \\
\hline 6 & sedang & sedang & menengah & ada \\
\hline 7 & sedang & sedang & menengah & ada \\
\hline 8 & sedang & rendah & rendah & tidak ada \\
\hline 9 & sedang & sedang & menengah & tidak ada \\
\hline 10 & sedang & rendah & rendah & tidak ada \\
\hline & & & & \\
\hline & & & & \\
\hline & & & & \\
\hline & & & & \\
\hline 133 & sedang & sedang & menengah & ada \\
\hline 134 & sedang & sedang & rendah & tidak ada \\
\hline 135 & sedang & rendah & rendah & tidak ada \\
\hline 136 & sedang & rendah & rendah & tidak ada \\
\hline 137 & sedang & sedang & tinggi & tidak ada \\
\hline 138 & sedang & sedang & menengah & ada \\
\hline
\end{tabular}




\subsection{Modelling Phase (Fase Pemodelan)}

Pada tahap pemodelan ini, data yang sudah diklasifikasikan selanjutnya di proses dengan beberapa pemodelan. Adapun pemodelan yang dimaksud adalah algoritma Nä̈ve Bayes.

\subsection{Algoritma Nä̈ve Bayes}

Dari proses di atas, dilakukan perhitungan Algoritma Naïve Bayes menggunakan data training dan data testing sebagai data uji. Berikut perhitunan menggunakan Algoritma Nä̈ve Bayes:

a. Baca Data Training

Di bawah ini merupakan data training yang digunakan dalam melakukan proses perhitungan Nä̈ve Bayes.

Tabel 6. Data Training

\begin{tabular}{|c|c|c|c|c|}
\hline No. & Suhu(Celcius) & Kelembaban[\%] & CurahHujan(mmihari) & Serangan Hama \\
\hline 1 & sedang & sedang & menengah & ada \\
\hline 2 & sedang & sedang & menengah & ada \\
\hline 3 & sedang & rendah & rendah & tidak ada \\
\hline 4 & sedang & rendah & menengah & tidak ada \\
\hline 5 & sedang & sedang & menengah & ada \\
\hline 6 & sedang & sedang & menengah & ada \\
\hline 7 & sedang & sedang & menengah & ada \\
\hline 8 & sedang & rendah & rendah & tidak ada \\
\hline 9 & sedang & sedang & menengah & tidak ada \\
\hline 10 & sedang & rendah & rendah & tidak ada \\
\hline & & & & \\
\hline & & & & \\
\hline & & & & \\
\hline & & & & \\
\hline 133 & sedang & sedang & menengah & ada \\
\hline 134 & sedang & sedang & rendah & tidak ada \\
\hline 135 & sedang & rendah & rendah & tidak ada \\
\hline 136 & sedang & rendah & rendah & tidak ada \\
\hline 137 & sedang & sedang & tinggi & tidak ada \\
\hline 138 & sedang & sedang & menengah & ada \\
\hline
\end{tabular}

Setelah mengetahui data training, selanjutnya data tersebut akan diuji menggunakan data testing sebagai berikut,

Tabel 7. Data Testing

\begin{tabular}{|c|l|c|c|c|c|}
\hline Kecamatan & Waktu & Suhu & Kelembaban & Curah Hujan & Serangan Hama \\
\hline Ciampea & Januari, 2019 & 28,1 & 88 & 200 & $?$ \\
\hline
\end{tabular}

Data testing di atas kemudian diklasifikasikan berdasarkan data preparation (data transformation).

Tabel 8. Data Testing Transformation

\begin{tabular}{|c|c|c|c|c|c|}
\hline Kecamatan & Waktu & Suhu & Kelembaban & Curah Hujan & Serangan Hama \\
\hline Ciampea & Januari, 2019 & Sedang & Sedang & Menengah & $?$ \\
\hline
\end{tabular}

b. Hitung $\mathrm{P}(\mathrm{C} 1)$ pada setiap Class

Untuk menghitung Probabilitas class, yaitu :

$$
P(C 1)=\frac{\text { Class serangan hama }=\text { "ADA" }}{\text { Jumlah data uji }}
$$


$\mathrm{P}(\mathrm{C} 2)=\frac{\text { Class serangan hama }=\text { "TIDAK ADA" }}{\text { Jumlah data uji }}$

1. $\mathrm{P}(\mathrm{ADA})=\frac{57}{138}=0.41304347826087$

2. $\mathrm{P}(\mathrm{TIDAK} A D A)=\frac{81}{138}=0.58695652173913$

c. Hitung probabilitas pada setiap kriteria

$\mathrm{P}(\mathrm{H} \mid \mathrm{X})=\frac{\mathrm{P}(\mathrm{X} \mid \mathrm{H}) \cdot \mathrm{P}(\mathrm{H})}{\mathrm{P}(\mathrm{X})}$

1) Suhu $=$ Sedang

$\mathrm{P}($ Suhu $=$ Sedang $\mid$ Serangan Hama $=\mathrm{ADA})=\frac{57}{57}=1$

$\mathrm{P}($ Suhu $=$ Sedang $\mid$ Serangan Hama $=$ TIDAK ADA $)=\frac{81}{81}=1$

2) Kelembaban $=$ Sedang

$\mathrm{P}($ Kelembaban $=$ Sedang $\mid$ Serangan Hama $=\mathrm{ADA})=\frac{57}{57}=1$

$\mathrm{P}($ Kelembaban $=$ Sedang $\mid$ Serangan Hama $=$ TIDAK ADA $)=\frac{19}{81}=$ 0.23456790123457

3) Curah Hujan $=$ Menengah

$\mathrm{P}($ Curah Hujan=Menengah $\mid$ Serangan Hama $=$ ADA $)=\frac{56}{57}=0.98245614035088$

$\mathrm{P}($ Curah Hujan=Menengah $\mid$ Serangan Hama $=$ TIDAK ADA $)=\frac{8}{81}=$ 0,098765432098765

d. Perkalian nilai probabilitas pada setiap class

1) Probabilitas ADA

$$
\begin{aligned}
& =\frac{57}{138} * \frac{57}{57} * \frac{57}{57} * \frac{56}{57} \\
& =0.41304347826087 * 1 * 1 * 0.98245614035088 \\
& =0.40579710144928
\end{aligned}
$$

2) Probabilitas TIDAK ADA

$$
\begin{aligned}
& =\frac{81}{138} * \frac{81}{81} * \frac{19}{81} * \frac{8}{81} \\
& =0.58695652173913 * 1 * 0.23456790123457 * 0.098765432098765 \\
& =0.013598139202004
\end{aligned}
$$

e. Hitung Persentase Keakurasian Kelulusan

1) Akurasi Persentase ADA $=\left(\frac{n A D A}{n T I D A K ~ A D A+n A D A}\right) * 100 \%$

$$
\begin{aligned}
& =\left(\frac{0.40579710144928}{0.013598139202004+0.40579710144928}\right) * 100 \% \\
& =96.76 \%
\end{aligned}
$$

2) Akurasi Persentase

$$
\begin{aligned}
& \text { TIDAK ADA }=\left(\frac{\mathrm{nTIDAK} \text { ADA }}{\mathrm{nADA}+\mathrm{nTIDAK} \text { ADA }}\right) * 100 \% \\
& =\left(\frac{0.013598139202004}{0.40579710144928+0.013598139202004}\right) * 100 \% \\
& =3.24 \%
\end{aligned}
$$


f. Membandingkan Nilai Akurasi

Dari hasil tersebut menyatakan $\mathrm{P}(\mathrm{X} \mid \mathrm{C} 1)>\mathrm{P}(\mathrm{X} \mid \mathrm{C} 2)$ atau $\mathrm{P}(\mathrm{X} \mid \mathrm{C} 2)<\mathrm{P}(\mathrm{X} \mid \mathrm{C} 1)$

g. Hasil

Berdasarkan data training yang berhasil diklasifikasikan 138 data training yang di uji pada data serangan hama. Metode Naive Bayes berhasil memprediksi adanya serangan hama dengan persentase keakuratan sebesar $96.76 \%$.

\section{HASIL}

Dari analisa sistem berjalan yang ada saat ini, dibuatlah sebuah rancangan usulan yang dapat membantu dalam mengetahui prediksi serangan hama berdasarkan data klimatologi sehingga mempermudah pemberian informasi untuk pihak terkait. Rancangan usulan yaitu suatu sistem yang membantu pemberian informasi mengenai prediksi serangan hama yang akurat.

\subsection{Halaman Login}

Halaman login merupakan langkah pertama yang harus dilewati oleh admin maupun staf (penyuluh) sebelum masuk ke dalam aplikasi. Pada halaman login ini, admin dan staf terlebih dahulu memasukkan username dan password sebelum masuk ke halaman utama aplikasi.

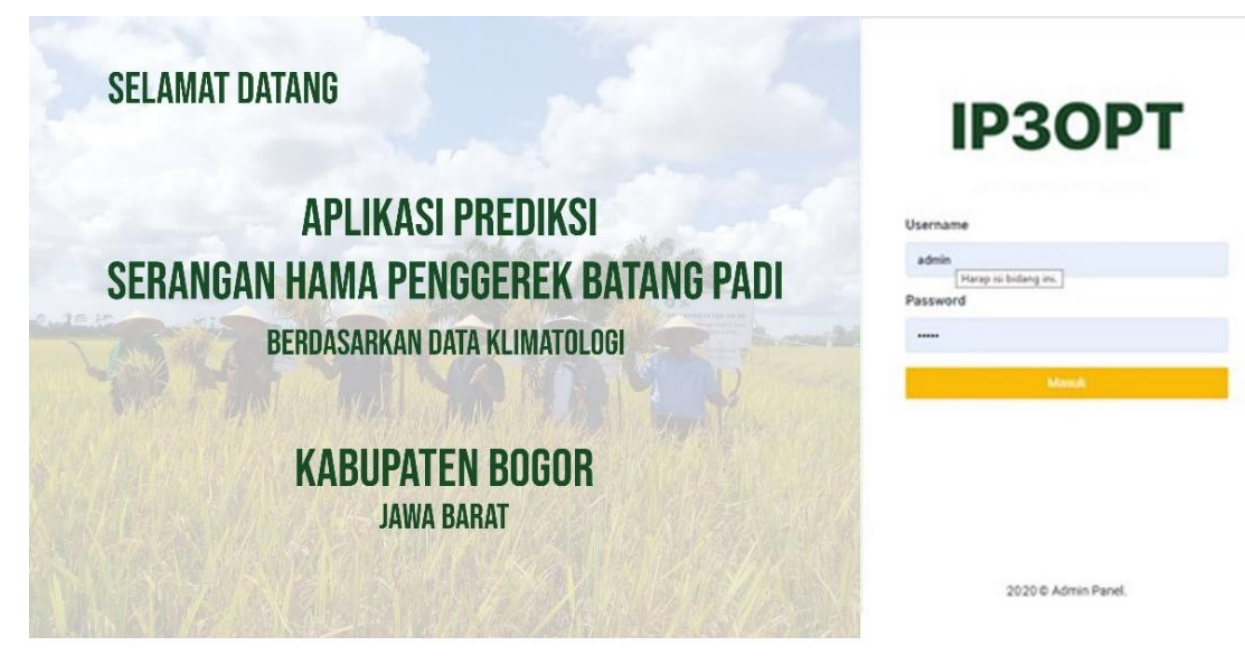

Gambar 3. Halaman Login

\subsection{Halaman Utama}

Halaman utama ini terbagi atas dua yaitu halaman utama admin dan halaman utama staf. Pada halaman ini, admin dan staf dapat melakukan testing untuk prediksi serangan hama. 


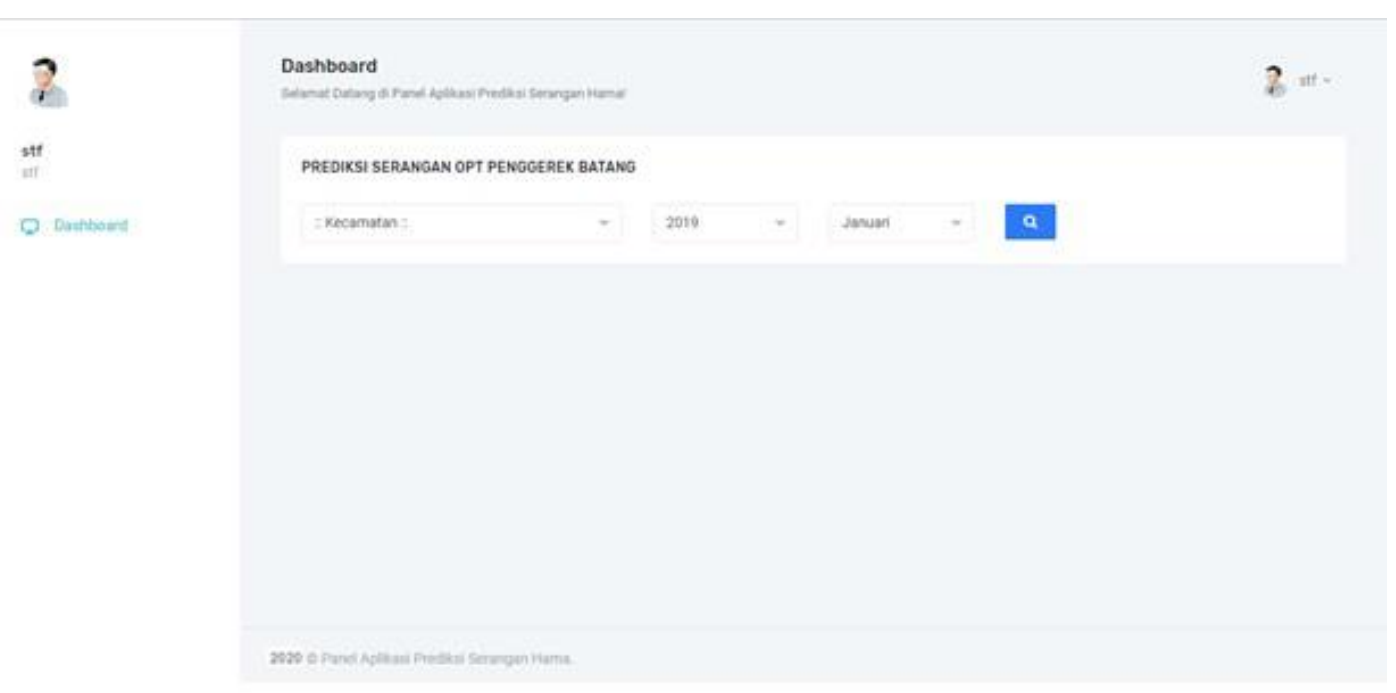

Gambar 4. Halaman Utama

\section{KESIMPULAN}

Berdasarkan hasil penelitian dan pembahasan yang telah dilakukan dapat diambil beberapa kesimpulan, antara lain:

1. Aplikasi ini memberikan informasi kepada pihak balai dalam memprediksikan akan adanya serangan hama penggerek batang di kabupaten Bogor sebagaimana tugasnya dalam melakukan pengawasan, peramalan, dan proteksi tanaman pangan dan holtikultura terhadap organisme pengganggu tanaman seperti hama.

2. Aplikasi ini memberikan kemudahan penyuluh dalam memberikan informasi kepada petani mengenai ramalan serangan hama dalam upaya mengantisipasi kerugian yang diakibatkan oleh hama.

3. Pengaplikasian metode Nä̈ve Bayes dalam aplikasi prediksi yang dibangun memiliki nilai keakuratan yang cukup tinggi terhadap probabilitas class ADA yaitu sebesar $96.76 \%$.

\section{DAFTAR PUSTAKA}

[1] R. Bayindir, M. Yesilbudak, M. Colak, and N. Genc, "A novel application of naive bayes classifier in photovoltaic energy prediction,” Proc. - 16th IEEE Int. Conf. Mach. Learn. Appl. ICMLA 2017, vol. 2017-Decem, pp. 523-527, 2017, doi: 10.1109/ICMLA.2017.0-108.

[2] L. Suada, I. D. Wijaya, and E. Rohadi, "Sistem Pakar Identifikasi Hama dan Penyakit Tanaman Tebu Menggunakan Metode Naïve Bayes,” Politek. Negeri Malang, 2016.

[3] T. Wahyono and Subanar, "Rancang Bangun Sistem 'Permadi' : Peringatan Dini Serangan Hama Tanaman Padi Berbasis Data Historis Klimatologi,” J. Sist. Komput., vol. 2, no. 1, pp. 9-16, 2012.

[4] Suprihati, Yuliawati, H. Soetjipto, and T. Wahyono, "Farmers Perception and Adaptation of Tobacco-Vegetables Cultivation toward Climate Change Phenomena at Tlogolele Village, Selo Sub District, Boyolali Regency,” J. Mns. dan Lingkung., vol. 22, no. 3, pp. 326-332, 2015.

[5] M. F. Rifai, H. Jatnika, and B. Valentino, "Penerapan Algoritma Naïve Bayes Pada Sistem Prediksi Tingkat Kelulusan Peserta Sertifikasi Microsoft Office Specialist (MOS)," Petir, vol. 12, no. 2, pp. 131-144, 2019, doi: 10.33322/petir.v12i2.471. 
[6] M. F. Rifai, D. T. Kusuma, and M. Y. Sudirman, "Penerapan Metode Triple Exponential Smoothing Pada Sistem Prediksi Keuntungan Bisnis Ayam Broiler Guna Meningkatkan Pengelolaan Keuangan Peternak," Kilat, vol. 8, no. 2, 2019, doi: 10.33322/kilat.v8i2.551.

[7] C. Pete et al., "Crisp-Dm 1.0," Cris. Consort., p. 76, 2000.

[8] D. Feblian and D. U. Daihani, "Implementasi Model Crisp-Dm Untuk Menentukan Sales Pipeline Pada Pt X,” J. Tek. Ind., vol. 6, no. 1, pp. 1-12, 2017, doi: 10.25105/jti.v6i1.1526.

[9] Suendri, "Implementasi Diagram UML (Unified Modelling Language) Pada Perancangan Sistem Informasi Remunerasi Dosen Dengan Database Oracle (Studi Kasus: UIN Sumatera Utara Medan),” J. Ilmu Komput. dan Inform., vol. 3, no. 1, pp. 1-9, 2018, [Online]. Available: http://jurnal.uinsu.ac.id/index.php/algoritma/article/download/3148/1871.

[11] Prasatya A, Siregar RR, Arianto R. Penerapan Metode K-Means Dan C4. 5 Untuk Prediksi Penderita Diabetes. PETIR: Jurnal Pengkajian dan Penerapan Teknik Informatika. 2020 Mar 22;13(1):86-100.

[12] Budiana ND, Siregar RR, Susanti MN. Penetapan Instruktur Diklat Menggunakan Metode Clustering K-Means dan Topsis Pada PT PLN (Persero) Udiklat Jakarta. PETIR: Jurnal Pengkajian dan Penerapan Teknik Informatika. 2019 Aug 6;12(2):111-21.

[13] Siregar RR, Siregar ZU, Arianto R. Klasifikasi Sentiment Analysis Pada Komentar Peserta Diklat Menggunakan Metode K-Nearest Neighbor. KILAT. 2019 May 17;8(1).

[14] D. Wira, T. Putra, and R. Andriani, "Unified Modelling Language ( UML ) dalam Perancangan Sistem Informasi Permohonan Pembayaran Restitusi SPPD,” TEKNOIF, vol. 7, no. 1, 2019.

[15] Fitriani Y, Rifai MF, Sudirman MY. Penentuan Jumlah Kelas Matakuliah Menggunakan Fuzzy Tsukamoto dan Metode K-Means Cluster. PETIR: Jurnal Pengkajian dan Penerapan Teknik Informatika. 2019 Sep 10;12(2):196-211. 